\title{
Water resources management exploration and practice for the project to save water and increase grain yield in four provinces of north east China
}

\author{
L. Chen \& Y. Zhang \\ Songliao Water Resources Commission, Ministry of Water Resources, \\ PR China
}

\begin{abstract}
The Project of Saving Water and Increasing Grain Yield in Four Provinces of Northeast China (hereinafter referred to as PWG) is an important agriculture saving water irrigation project dominated and implemented by government in China. Its purpose is to increase grain yield and production capacity by the effective utilization of local water resources. According to the specific requirements of the most stringent water resources management system, the exploration and practice of complete process water resources management of the project is implemented so that it is able to adapt to the local water resources conditions and assure sustainable benefit generation of the project. The water resources management measures of the project are summarized in this paper in order to provide a reference for water resources management of a similar project. Keywords: water resources management, Project of Saving Water and Increasing Grain Yield.
\end{abstract}

\section{Introduction}

The cultivated land area of China is about $10 \%$ of the world's cultivated land, but the population of China is about $22 \%$ of the world's population. So the food security of more than a billion Chinese people is always an important strategic issue for the Chinese government. Meanwhile, China is a water resources scarcity country. The agricultural water use is more than $60 \%$ of the total water use of all industries in China. The water resources imbalance of supply and demand has 
become the main restraining factor of stable grain yield increase. The Songhua River and Liao River Basin (hereinafter referred to as Songliao River Basin) is the most important grain production region, and is also the region for the greatest potential capacity for grain yield increase in China. The basin takes an important strategic position in ensuring national food security.

The Songliao River Basin is covered by a dense river network and has a rich river system, with the two big water systems of the Songhua River and Liao River, the international boundary rivers (lakes) and those independent sea-entering rivers. Its administrative divisions include the three provinces of Liaoning, Jilin and Heilongjiang, the eastern four districts of Inner Mongolia Autonomous Region and one part of Chengde City of Hebei Province in Northeast China, with a total area of 1.2490 million $\mathrm{km}^{2}$. The basin has the geomorphic feature with mountains around its west, north and east, Bohai Sea and Huanghai Sea on its south, the broad Songnen Plain and Liaohe Plain respectively in its middle and south, and Sanjiang Plain in its northeast. The main rivers include Erguna River, Amur River, Songhua River, Wusuli River, Suifen River, Tumen River, Liao River, Yalu River and independent sea-entering rivers. The average annual total amount of water resources of the whole basin is 199 billion $\mathrm{m}^{3}$. The Songliao River Basin is located mainly in the northern temperate zone under the influence of monsoon, with a part in the cold temperate zone. The average annual precipitation ranges from 300 to $1200 \mathrm{~mm}$, decreasing successively from the southeast to the northwest. A disproportionate water flow and huge disparity in annual distribution happens in the Basin. Songliao Water Resources Commission (hereinafter referred to as SWRC), an agency of the Ministry of Water Resources taking charge of the Songliao River Basin, is a public institution with administrative functions, representing the Ministry of Water Resources of China to perform the water administrative functions in its river basins.

The natural conditions of the Songliao River Basin are preferable. Land resources are rich. But land and water resources are not matched. For a long time, the agricultural irrigation infrastructure has been unsubstantial and the irrigation efficiency is low. The water scarcity coexists with the water waste. The water scarcity has become a key restrictive factor on potential productivity development of agriculture in the four provinces of Northeast China. To improve the national grain productivity and develop the land resources of the four provinces, the PWG was initiated by the Chinese government at the end of 2011. It is a highly efficient water-saving irrigation project of the largest scale, the largest one-time investment and the most centralized time schedule in China so far. The project will construct 38 million mu (about 2.53 million ha, $1 \mathrm{ha}=15 \mathrm{mu}$ ) efficient water-saving irrigation infrastructure with 38 billion Yuan RMB investment during 2012-2015. The main water source of the project is groundwater. It will exploit the potential grain productivity, promote modern agriculture, fundamental construction, increase rural income and improve the ecological environment so that the economic society can realize sustainable development. 


\section{Possible problems caused by the PWG}

The PWG is a systematic project. All kinds of factors should be considered as a whole otherwise many potential problems could be caused. The problems could be as follows:

I. Project layout is unreasonable. The current water resources development and utilization percentage is very high in some regions. The water resources capacity for irrigation development is very small or none. These regions are not suitable for further agricultural irrigation development. In addition, the precipitation condition is preferable for grain growing in other regions. The rainfall can meet the demand of agricultural irrigation and irrigation is not necessary in these regions. If the above factors are not considered, the PWG will not sustain development or the water resources and investment will be wasted greatly.

II. Irrigation mode is unreasonable. The selected irrigation mode should fit with the local climate conditions, type of water source, landform and crop types, otherwise the irrigation technical methods and engineering types will be unfeasible.

III. Ecological and environmental issues might be caused in some regions. If the groundwater is exploited continuously for the project in high degree of groundwater development area or groundwater over-development area, the groundwater level will decline continuously and the over-development of groundwater will happen. The ecological and environmental issues on some sensitive regions of wetlands, lakes and rivers will be caused in some more serious situations.

\section{Water resources management measures on the PWG}

The most stringent water resources management system was implemented by the central government of China at the beginning of 2011 on the basis of systematic summarization on Chinese water resources management practice and experience according to the new requirements and situation of water resources. The system established three red lines with water resources development and utilization control index, water-use efficiency control index and pollutant discharge to the water functional area control index. It also established four specific management systems including water resources development and utilization control system, water-use efficiency control system, pollutant discharge control system, responsibility and assessment system. The reasonable water resources development, utilization, saving and protection are facilitated, and the economic society development will adapt to water resources and environment supporting capacity through the system.

The complete process water resources management on the PWG was proposed by the Chinese government according to the specific requirements of the most stringent water resources management system in order to guarantee PWG layout adapting to the regional water resources conditions, determine scientifically irrigation mode and scale, improve the water resources utilization efficiency and 
benefit, avoid causing groundwater ecological and environmental issues. The water resources condition was taken as a control requirement and precondition of project implementation. The water resources assessment must be carried out before the project implementation. The project implementation area must be selected according to the conclusion of water resources assessment. The veto system with only one vote of water resources assessment was put into practice. For carrying through the system, Notice on Implementing PWG Water Resources Assessment was issued specifically by the Ministry of Water Resources. The specific management regulation on PWG water resources assessment was formulated by the Ministry of Water Resources.

\subsection{Implement PWG water resources balance analysis and assessment}

The highly efficient water saving irrigation area of the PWG is 380 million mu, including 150 million $\mathrm{mu}$ in Heilongjiang Province, 90 million $\mathrm{mu}$ in Jilin Province, 60 million mu in Liaoning Province, 80 million mu in Inner Mongolia Autonomous Region. 187 countries are involved in the project. The provincial and overall country-level implementation plans were requested to be formulated in order to implement the PWG better. The Ministry of Water Resources demanded the water resources balance analysis should be completed for overall provincial implementation plans, the water resources assessment should be completed for overall country-level implementation plans. Meanwhile, water resources balance analysis and assessment compiling technique requirements were formulated. It was confirmed that the water resources balance analysis on overall provincial implementation plans should be finished first, then the water resources assessment on overall country-level implementation plans can be compiled on this basis. The water resources balance analysis and assessment must comply with the Water Resources Comprehensive Planning of the Songliao River Basin approved by the State Council of China. The irrigation development scale and layout should be decided according to the requirements of water saving, grain yield and increase in benefits. The rationality of water exploitation and utilization, and the influence on the ecology and environment should be studied comprehensively so that the resources development and utilization control index will not be exceeded.

The water resources balance analysis emphasis on overall provincial implementation plans should be that if the project layout will adapt to local water resources condition, if the project layout will conform with the total amount of water resources utilization and water-use efficiency control index, if the irrigation method and scale are suitable, and what accumulated impacts of the project implementation are.

The water resources assessment emphasis on the overall country-level implementation plans should be that what the current water resources development and utilization situation in the project area is, why water source is selected, what the water-intake way is, if the irrigation method and scale are suitable, what the water drawing impacts on ecological environment and rights and interests of other legal water users are.

The water resources balance analysis and assessment must be undertaken by a company with a qualification in water resources assessment. The qualified 
company and the complete process of report formulation should be supervised and managed by SWRC and provincial departments of water administration.

\subsection{Stringent examination and approval of water resources assessment}

The water resources balance analysis and assessment report should be examined and approved hierarchically. The water resources balance analysis of overall provincial implementation plans will be examined and approved along with overall provincial implementation plans by the Ministry of Water Resources. For overall country-level implementation plans, if the water-saving irrigation area is more than or equal to 300 thousand mu, the water resources assessment report will be examined and approved first by the provincial department of water administration and finally by SWRC; if the water-saving irrigation area is less than 300 thousand $\mathrm{mu}$, the water resources assessment report will be examined and approved finally by the provincial department of water administration, but the assessment report with the area between 300 to 100 thousand mu should be reexamined by SWRC (Ministry of Water Resources, PRC [1]).

The requirements for the technical examination were put forward clearly. The requirements include that the exploitation of ground water should be reasonable, deep confined water mining should be forbidden, the balance of ground water exploitation and recharge should be kept. The high efficiency and ware-saving irrigation mode, such as trickle irrigation and sprinkling irrigation etc., should be chosen according to the local natural conditions. All kinds of irrigation quota and water supply volume should be calculated scientifically and exactly. To avoid ecological and environmental issues arising, the new irrigation area should not be developed in some regions, such as over-development regions of groundwater, the region of water utilization volume approximating or exceeding water resources development and utilization control index, fragile regions of ecology and environment. If the project scale and layout do not adapt to the local water resources condition, the reasonable adjustment must be made. If the water resources development has a significant impact on groundwater, the legal rights of other water users or public interest of society, the technical examination on assessment report should not be passed.

After the water resources assessment report is agreed by specialists, it will be approved by the agency or departments having corresponding administration authority. The project owners should take water-drawing permission procedures in accordance with relevant regulations. The water resources management of the PWG will be included in routine water resources management system.

\subsection{Stringent supervision and management of water use}

The water resources assessment examination and approval are preconditions for the project implementation, but supervision and management on water drawing and use are the most important steps during the project implementation and after the project construction. The rational monitoring scheme on water drawing and use should be proposed in the water resources assessment report. The metering facilities of water drawing must be installed during the project construction. The investment for the metering facilities should be contained in the investment 
arrangement plan of the project. The facilities construction should be contained in the construction scale of the project. The dynamic monitoring of water drawing volume and quality for irrigation should be performed so that the groundwater over-development and ecological and environmental issues can be avoided. If the project implementation plan was adjusted, its water resources assessment report must be. The re-formulated assessment report should be re-examined and reapproved by the corresponding agency or department.

Although water resources assessment reports have been examined and approved, the risk of some project construction scale and layouts unadapting to the local water resources condition still exists due to the tight schedule, lots of examination work, basic groundwater data scarcity, and extreme difficulty in groundwater assessment. To prevent the risk, SWRC and provincial departments of water administration carried out the post evaluation on water resources assessment of the completed project in 2014. The post evaluation includes the scientificity and reasonability of water resources assessment, impact analysis on ecological environment due to project implementation, assessment on the practice of water resources protection measures. If the problems are discovered through the post evaluation, they should be solved immediately.

The supervision, inspection and appraisal mechanism were established in order to ensure water-saving irrigation infrastructure operating in order to obtain the well water-saving effect. The on-site inspections on the PWG yearly implementation of 2012 and 2013 were carried out respectively by SRWC authorized by the Ministry of Water Resources at the beginning and end of 2014. The inspection included project construction and management situations, performance effects, water resources management measures practice situations. The rectification measures and program were put forward according to the issues found. The issues included that the project was failing in accordance with its overall implementation plan and water resources assessment report, the irrigation scale and mode were adjusted without authorization, and groundwater monitoring facilities were not installed in time. All issues were requested to be settled without delay. The PWG irrigation water volume will be included in the total amount of local water resources development and utilization control. The total amount of local water resources development and utilization of all countries cannot exceed the control index approved by the State Council.

\section{Water resources management effects on the PWG}

The water source, water use volume and groundwater well spacing scheme of the PWG were determined scientifically according to the water resources assessment report. It guaranteed that the irrigation scale and layout adapted to the local water resources condition. Through implementing the water resources assessment, the unreasonable irrigation area of 4.93 million mu were adjusted to other reasonable regions; the unreasonable irrigation area of 1.05 million mu were reduced; the construction of 55.7 thousands unnecessary groundwater wells were canceled; and the water drawing volume of 386 million $\mathrm{m}^{3}$ were saved ( $\mathrm{Xu}$ [2]). 
The water resources assessment of PWG is the first large scale water resources assessment work for an agricultural project in China. The work provided the important foundation for the PWG decision making. The water resources, ecological and environmental protection awareness of the local people were increased through the water resources assessment. The groundwater wells layout was optimized. The investment was saved because the construction of many unnecessary groundwater wells was canceled. The local water resources utilization efficiency and benefit were increased. The highly efficient water-saving irrigation technique and mode adapting to local natural conditions were explored. The watersaving irrigation quotas were established scientifically. All the works established the technical base for other agricultural water-saving projects in similar regions. The water resources assessment technical requirements and water resources management measures on agricultural irrigation projects were explored. The experiences were accumulated for improving water resources management on agricultural water-saving irrigation.

\section{Conclusions}

The PWG is a large scale systematic project initiated by the government. The water resources assessment is the core of water resources management on the project. The most stringent water resources management system was carried out firmly in the water resources assessment work. The irrigation scale, layout and mode of the project were determined scientifically according to the local water resources conditions. The water source selection and groundwater well spacing scheme of the PWG were confirmed rationally. The water resources real time monitoring schemes for the project were put into practice. The real time monitoring provided the technical base for the project implementation and management. The post evaluation of water resources assessment, supervision and inspection on the project guaranteed the water resources assessment reports and approval documents being put in practice. The found problems during supervision and inspection were solved and rectified in time. Through the complete process water resources management from planning to implementation of the project, the social, economic and ecological benefits of the PWG have been produced, and the water-saving and grain yield increasing have been realized.

\section{References}

[1] Notice on Implementing Water Resources Assessment on Project of Saving Water and Increasing Grain Yield in Four Provinces of Northeast China, issued by Ministry of Water Resources, PRC. Document Number 261, pp. 24, 2012.

[2] $\mathrm{Xu}$ W., Implement Strictly Water Resources Assessment Management System, Convoy Project of Saving Water and Increasing Grain Yield in Four Provinces of Northeast China, China Water Resources, Volume 11, pp. 9, 2014. 